\title{
Higher Education and Digitalization of the Economy: The Case of Russian Regions
}

\author{
Ekaterina Koroleva $^{1 *}$, Anna Kuratova ${ }^{1}$ \\ ${ }^{1}$ Graduate School of Industrial Economics, Peter the Great St. Petersburg Polytechnic University, St. \\ Petersburg, Polytechnicheskaya, 29, 195251, Russia
}

\begin{abstract}
Building on the resource-based theory, we examine the association between the digitalization of the economy and the quality of higher education in Russian regions. We use the regression model to analyze data collected in Russian regions from 2011 to 2018. The quality of higher education is measured by the education potential in the regions. Regional factors of economic digitalization are categorized by mobile and Internet activities, technological background, and innovation activities. The information database contains official dates drawn from federal and regional statistical sources. The results showed that regions that had higher levels of innovation activities had a higher quality of higher education. On the contrary, mobile and Internet activities had a weakly negative influence on the quality of higher education. Our results are controversial with respect to the technological background of the region and its influence on the quality of higher education. Nonetheless, the study provides insights into the resource-based theory, demonstrating that the factors of economic digitalization increase the competitive advantage of the region regarding education, and they play an important role in regional sustainable development.
\end{abstract}

Keywords: Digitalization; Education potential; Quality of education; Regional development

\section{Introduction}

The new trend to digitalization has penetrated each sphere of modern life, including education. Recently, the education process has been significantly transformed by the emergence of digital platforms, mobile educational applications, audio classes, and so on. The transformation of education has led to the increased accessibility of education, as well as changes in the skills acquired from communication to visibility and involvement in the educational process (Shcherbina, 2020). Most previous studies have analyzed the attitudes and satisfaction of students with the digitalization of education (Chen et al., 2020; Popova et al., 2020) and the development of convenient application interfaces (Korableva et al., 2019). To the authors' knowledge, no previous study has interpreted digitalization as a competitive resource in regions and a tool for upgrading the quality of education.

The theoretical background of this research is the resource-based theory (Barney et al., 2001). We propose that digitalization in territories, particularly regions, is a rare, difficult-to-imitate resource that influences the quality of higher education. We evaluate the association between digitalization and the quality of education in the case of Russian regions. One of the characteristic features of Russia is the unsustainable development of its 
regions, which is due to the uneven distribution of resources (e.g., human, social, material, etc.). This imbalance has been the source of serious long-term threats to and negative influences on the stability of the country's development overall. Because of these characteristics, Russia is an interesting case for research.

In this study, we apply a cross-sectional regression model to a set of data on Russian regions collected from 2011 to 2018. The research was run before the COVID pandemic, so the influence of the COVID pandemic was not analyzed. The quality of higher education is measured by the education potential of the region. Digitalization factors are distributed according to the following categories: mobile and Internet activities; technological background; and innovation activities in the region. This research is based on information drawn from regional statistical sources (Federal Service State Statistics, 2020).

The results of our study showed that regions with higher levels of innovation activity had a higher quality of higher education. On the contrary, mobile and Internet activities had a weak negative influence on the quality of higher education in the regions. Our results are controversial regarding the influence of the regions' technological background on the quality of higher education. Nonetheless, the study demonstrates that the factors of innovation and mobile and Internet activities in the region led to increased competitive advantages in education, and they played an important role in sustainable development.

The article contributes to the literature on the resource-based theory (Barney, 1991; Rothaermel, 2012; Sharma et al., 2019), in which digitalization is considered a difficult-toimitate resource for improving the quality of education in regions. It could be concluded that digitalization would have a positive influence on the assessment of education in Russian regions because, in general, the implementation of digital technologies improves its quality and contributes to the further development of the economy.

The paper is structured as follows. Section 2 provides a literature review. The data collection and methods are described in section 3 , and the results are discussed in section 4. Finally, section 5 provides a discussion of the findings and concludes the paper.

\section{Literature View}

According to the resource-based theory (RBV), resources are a key factor in the superior performance of the region. If a resource is difficult to imitate, it enables the subject to gain and sustain a competitive advantage (Rothaermel, 2012). The RBV emerged in the 1980s (Wernerfelt, 1984; Barney, 1991; Prahalad \& Hamel, 1997). The main idea of this theory is that subjects should examine themselves to find the sources of competitive advantage instead of searching for it in a competitive environment (Sharma et al., 2019).

It is assumed that some factors in the digitalization of the economy are difficult-toimitate resources, which, in regions, creates a stronger competitive advantage in education. In this study, the factors in the digitalization of a regional economy are classified according to mobile and Internet activities, technological background, and innovation activities in the region. Internet and mobile technologies provide opportunities for people worldwide to access quality educational services regardless of their location (Mansell \& When, 1998; Kenneth, 2008). Previous studies showed increased student academic achievement when computers and mobiles were used to support classroom instruction (Usarova, 2018). The findings revealed increased achievement by both regular and special needs students, improved attitudes toward learning, and increased self-esteem.

However, the evidence of the influence of the Internet and mobile activities on students is contradictory. Although they provide information resources, and they have led to a new model of the education process, Internet and mobile activities have negative influences on 
students, such as addiction and gambling (Chen, 2019). Therefore, we propose the following hypothesis:

H1: Mobile and Internet activities have a positive influence on the quality of higher education in the region.

The region's technological background will ensure the high-quality digital transformation of education, which will have a positive effect on the quality of education in general. Moreover, the technological background will ensure the reorientation of education to meet new challenges in the labor market (Dachyar et al., 2015; Plotnikova, 2019; Suwartha and Berawi, 2019). The positive influence of technological background on the educational process was shown by Sangrà and González-Sanmamed (2010). In their research, the authors analyzed the technological background as an innovation factor and concluded that the quality of the educational process depends on both the technological background and education methods. Therefore, the following hypothesis is stated:

H2: Technological background has a positive influence on the quality of higher education in the region.

In a technology-rich learning environment, students become more involved in and invest more in the learning process. Technology creates an environment that supports synergy, collaboration, and dynamic manual learning. Compared with traditional teaching methods, classrooms equipped with technology support the development of selfmotivation in the learning process. The number of colleges and universities that incorporate e-learning (or e-learning) is increasing although there are gaps in the research related to student adaptation. However, it has been found that infrequent users of technology have difficulty in adopting learning technologies, while frequent users of technology have been successful in creating a technology-enabled environment (Cervantes, 2017).

However, assigning a haphazard computer project to a group of students will not necessarily result in high testing results. For students to succeed, it is necessary first to show interest and motivation in using technologies (Velichenkova et al., 2017). The formation and implementation of innovative tools in Russian regional universities could contribute to the emergence of strong universities that are engaged in applied and fundamental research, closely interact with industry, and introduce knowledge in practical and scientific research (Medinsky, 2018). To achieve a tangible contribution by universities to the development of regional and local innovation, it is necessary to ensure complementarities and a balance between their missions. Therefore, the following hypothesis is stated:

H3: Innovation activities have a positive influence on the quality of higher education in the region.

\section{Data and Method}

The dataset used in this study contained 579 observations of Russian regions in the period from 2011 to 2018. According to the study goal, the dependent variable characterizes the quality of higher education. The explanatory variables reflect information about the digitalization of the regional economy.

The methodological approach was conducted in the following steps: (1) collect the dataset; (2) analyze the input information; (3) test the hypotheses; (4) check the viability of the analysis; and (5) interpret the results. 
Several approaches to assessing the quality of higher education systems are available. International rankings are the most popular and widespread. The disadvantage of such ratings is that they do not consider the territorial features of Russia. The country is characterized by the uneven and unbalanced development of individual territories, which includes regional digitalization. Therefore, it is difficult to consider the digitalization of the vast territories in the country (Sukhanova, 2015). To analyze the quality of higher education in the regions, we decided to use an approach suggested by Russian authors (Balatsky and Ekimova, 2009). We chose to focus on the education potential of regions as a criterion of the quality of higher education for the following reasons: the availability of source data; the simplicity of calculations; and the adaptability of the approach to Russian conditions. The criteria consisted of three main elements: educational services; financial stability; and scientific performance. A detailed calculation of the criteria was presented by its developers (Balatsky and Ekimova, 2009). Based on this previous research, we calculated the education potential of regions from 2011 to 2018.

The analysis of education potential of regions in 2018 compared with those in 2011 showed that the leaders were Moscow and St. Petersburg, which indicated that these cities are provided with educational services. They annually attract young people from over the country. It can be noted that the regions with high education potential have research institutes, which creates conditions for attracting teachers, postgraduates, and students to conduct research and development, as well as improving the quality of training and commercialization of scientific research. Despite insignificant changes in the position of the regions, the level of education potential showed a positive trend. The improvement of education in regions has been successful because of the introduction of upgraded educational technologies in the learning process and changes in the educational environment with the assistance of regional authorities. The analysis of several scientific studies (Regions of Russia, 2018) allowed the authors to compare quantitative indicators with qualitative indicators (i.e., mobile and Internet activities, technological background, and innovation activities in the regions), which were used as explanatory variables. The indicators of mobile and Internet activities' indicators were marked by the prefix MI_A. These indicators were the following: the share of organizations that used the Internet; the number of active subscribers to Internet access; the share of educational organizations having a website; and the share of educational organizations using distance learning technologies. To test H1, we considered the effects of the identified indicators on the dependent variable.

To test H2, we considered the association between indicators with the prefix T_A and the quality of higher education. This category of economic digitalization contained the following factors: the number of cellular communication subscriber devices; the share of digitalization of the network in urban areas; the number of personal computers; and the cost of technological innovation.

We measured the innovation activities in the region by the following indicators: the share of innovation activity in the organization; the ratio of inventive activity; the number of advanced production technologies; and the volume of shipped innovative activities. The effects of factors with a prefix I_A were identified to test H3.

The descriptive statistics of explanatory variables are presented in Table 1. 
Table 1 Variable definitions and descriptive statistics

\begin{tabular}{|c|c|c|c|c|c|c|}
\hline Variable & Description & Obs. & Mean & Std. Dev. & Min & Max \\
\hline MI_A_1 & $\begin{array}{l}\text { The share of } \\
\text { organizations using } \\
\text { Internet, \% }\end{array}$ & 674 & 78.43 & 10.70 & 32.43 & 97.75 \\
\hline MI_A_2 & $\begin{array}{l}\text { The number of active } \\
\text { subscribers of Internet } \\
\text { access, units }\end{array}$ & 666 & $314,166.00$ & $471,776.30$ & $1,313.00$ & $4,565,660.00$ \\
\hline MI_A_3 & $\begin{array}{l}\text { The share of } \\
\text { educational } \\
\text { organizations, having } \\
\text { website, } \%\end{array}$ & 650 & 99.41 & 3.64 & 50.00 & 100.00 \\
\hline MI_A_4 & $\begin{array}{l}\text { The share of } \\
\text { educational } \\
\text { organizations using } \\
\text { distance learning } \\
\text { technologies, \% }\end{array}$ & 592 & 62.18 & 25.49 & 0.00 & 100.00 \\
\hline T_A_1 & $\begin{array}{l}\text { The number of cellular } \\
\text { communication } \\
\text { subscriber devices, pcs. }\end{array}$ & 663 & $1,702.82$ & 363.81 & 20.60 & $3,022.60$ \\
\hline T_A_2 & $\begin{array}{l}\text { The share of } \\
\text { digitalization of the } \\
\text { network in urban areas, } \\
\%\end{array}$ & 665 & 89.57 & 10.27 & 8.80 & 100.00 \\
\hline T_A_3 & $\begin{array}{l}\text { The number of personal } \\
\text { computers, pcs./100 } \\
\text { people }\end{array}$ & 674 & 26.14 & 6.78 & 10.00 & 61.00 \\
\hline T_A_4 & $\begin{array}{l}\text { The costs of } \\
\text { technological } \\
\text { innovations, mln. rub. }\end{array}$ & 665 & $14,730.80$ & $30,167.19$ & 0.10 & $283,737.50$ \\
\hline I_A_1 & $\begin{array}{l}\text { The share of innovation } \\
\text { activity of } \\
\text { organizations, } \%\end{array}$ & 668 & 9.39 & 4.92 & 0.18 & 33.76 \\
\hline I_A_2 & $\begin{array}{l}\text { The ratio of inventive } \\
\text { activity, units }\end{array}$ & 652 & 1.14 & 1.11 & 0.02 & 10.28 \\
\hline I_A_3 & $\begin{array}{l}\text { The advanced } \\
\text { production } \\
\text { technologies, units }\end{array}$ & 666 & $2,663.92$ & $3,275.13$ & 8.00 & $20,649.00$ \\
\hline I_A_4 & $\begin{array}{l}\text { The volume of shipped } \\
\text { innovative activities, } \\
\text { mln. rub. }\end{array}$ & 667 & $43,674.01$ & $95,266.42$ & 0.00 & $910,869.10$ \\
\hline
\end{tabular}

Regarding mobile and Internet activities, around 78\% of organizations used the Internet. Note that around $99 \%$ of educational organizations had a personal website. This indicator had a low standard deviation. The high share was explained by the governmental requirements of educational organizations. The use of distance educational technologies in education was $62 \%$. Regarding the technological background, we focused on the sufficiently high share of digitalization of networks in urban areas. However, the range between minimum and maximum meanings was large. This trend was caused by the active implementation of regional programs. The number of personal computers was not high. On average, there were 26 computers per 100 people in the regions. The indicator reflecting the cost of technology investment remained low although it increased yearly during the study period. Increasing the country and regional budgets for this item would increase the 
country's competitiveness at the global level (Grinchak et al., 2020). In terms of innovation activities in the regions, the level of innovation activity in the organizations was low and accounted for only one-third of the companies, which were mainly concentrated in large cities. Because of the differences in the dimensions of the explanatory and dependent variables, the authors divided the former by 1,000,000.

In analyzing the input information, we conducted a correlation matrix of the explanatory variables to avoid the multicollinearity of the factors (Table 2). Using a multiple regression, this matrix provided a statistical adjustment to the correlations among the remaining variables.

Table 2 Correlation matrix

\begin{tabular}{|c|c|c|c|c|c|c|c|c|c|c|c|c|}
\hline & $Y$ & MI_A_1 & MI_A_2 & MI_A_3 & MI_A_4 & T_A_1 & T_A_2 & T_A_3 & T_A_4 & I_A_1 & I_A_2 & I_A_3 \\
\hline $\mathrm{Y}$ & 1.00 & & & & & & & & & & & \\
\hline MI_A_1 & 0.22 & 1.00 & & & & & & & & & & \\
\hline MI_A_2 & 0.62 & 0.33 & 1.00 & & & & & & & & & \\
\hline MI_A_3 & -0.03 & 0.13 & 0.03 & 1.00 & & & & & & & & \\
\hline MI_A_4 & -0.15 & -0.11 & -0.24 & 0.05 & 1.00 & & & & & & & \\
\hline T_A_1 & 0.31 & 0.12 & 0.38 & 0.09 & -0.04 & 1.00 & & & & & & \\
\hline T_A_2 & 0.13 & 0.02 & 0.22 & 0.08 & -0.03 & 0.22 & 1.00 & & & & & \\
\hline T_A_3 & 0.52 & 0.53 & 0.40 & 0.10 & -0.09 & 0.22 & 0.31 & 1.00 & & & & \\
\hline T_A_4 & 0.57 & 0.21 & 0.79 & 0.00 & -0.12 & 0.34 & 0.21 & 0.26 & 1.00 & & & \\
\hline I_A_1 & 0.42 & 0.21 & 0.39 & 0.02 & -0.07 & 0.18 & 0.04 & 0.18 & 0.47 & 1.00 & & \\
\hline I_A_2 & 0.51 & 0.03 & 0.50 & -0.03 & -0.15 & 0.09 & 0.00 & 0.21 & 0.35 & 0.39 & 1.00 & \\
\hline I_A_3 & 0.47 & 0.19 & $\underline{0.83}$ & -0.03 & -0.09 & 0.35 & 0.18 & 0.24 & $\underline{0.80}$ & 0.46 & 0.46 & 1.00 \\
\hline I_A_4 & 0.60 & 0.32 & 0.70 & -0.02 & -0.14 & 0.20 & 0.17 & 0.40 & 0.72 & 0.41 & 0.40 & 0.68 \\
\hline
\end{tabular}

The results shown in Table 2 revealed factors such as the number of active subscribers to Internet access (MI_A_2) and the costs of technological innovations (T_A_4). The advanced production technologies (I_A_3) and the costs of technological innovations (T_A_4) showed collinearity. Such strong correlations could lead to the distortion of the results of the model evaluation. Therefore, the number of active subscribers to Internet access (MI_A_2) and the costs of technological innovations (T_A_4) were excluded from the model.

The coefficients of asymmetry and kurtosis of the number of indicators (MI_A_1, T_A_1, T_A_2, I_A_1; I_A_2, I_A_3, I_A_4) were not equal to zero. The form of many indicators differed from the linear. Consequently, the functional form of these variables was changed to the most similar to normal distribution. For example, MI_A_1 was cubed.

As a result, the hypotheses were tested using the following regression model:

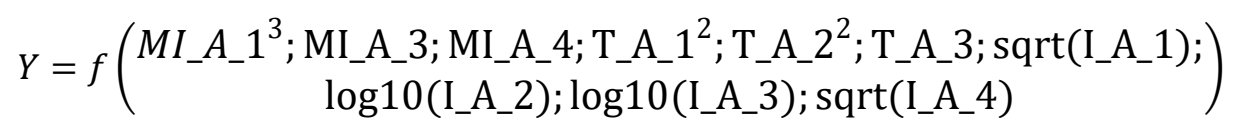

\section{Results}

The results of the step-by-step regression are presented in Table 3. Contrary to H1, the results showed a weakly negative relationship among mobile and Internet activities, and the quality of education in the regions. The share of educational organizations having a website (MI_A_3) was statistically significant but had low economic significance. The share of educational organizations using distance learning technologies (MI_A_4) was not statistically significant. 
Table 3 Education and digitalization of the economy

\begin{tabular}{|c|c|c|c|c|c|c|}
\hline Model & (1) & & $(2)$ & & (3) & \\
\hline \multirow{2}{*}{ MI_A_1 ${ }^{3}$} & -0.167 & $* * *$ & -0.177 & $* * *$ & -0.185 & $* * *$ \\
\hline & $(0.046)$ & & $(0.042)$ & & $(0.419)$ & \\
\hline \multirow{2}{*}{ MI_A_3 } & -4280.000 & $*$ & -4120.000 & * & -5610.000 & $* *$ \\
\hline & $(2490.000)$ & & $(2460.000)$ & & $(2180.000)$ & \\
\hline \multirow{2}{*}{ MI_A_4 } & -299.000 & & & & & \\
\hline & $(251.000)$ & & & & & \\
\hline \multirow{2}{*}{ T_A_12 } & 0.039 & $* * *$ & 0.039 & $* * *$ & 0.036 & $* * *$ \\
\hline & $(0.007)$ & & $(0.007)$ & & $(0.006)$ & \\
\hline \multirow{2}{*}{ T_A_22 } & -9.260 & $* *$ & -10.100 & $* *$ & -11.300 & $* * *$ \\
\hline & $(4.160)$ & & $(3.980)$ & & $(3.890)$ & \\
\hline \multirow{2}{*}{ T_A_3 } & 12400.00 & $* * *$ & 11800.00 & $* * *$ & 12200.00 & $* * *$ \\
\hline & $(1230.00)$ & & $\left(\begin{array}{ll}1 & 140.00\end{array}\right)$ & & $\left(\begin{array}{ll}1 & 120.00\end{array}\right)$ & \\
\hline \multirow{2}{*}{ sqrt(I_A_1) } & 44900.00 & $* * *$ & 36300.00 & $* * *$ & 36400.00 & $* * *$ \\
\hline & $\left(\begin{array}{lll}10 & 000.00\end{array}\right)$ & & $(8630.00)$ & & $(8470.00)$ & \\
\hline \multirow{2}{*}{ log10(I_A_2) } & 73500.00 & $* * *$ & 82200.00 & $* * *$ & 73700.00 & $* * *$ \\
\hline & $(9780.00)$ & & $(8630.00)$ & & $(7740.00)$ & \\
\hline \multirow{2}{*}{ log10(I_A_3) } & 10400.00 & & 10200 & & & \\
\hline & $\left(\begin{array}{ll}8 & 010.00\end{array}\right)$ & & $(6940.00)$ & & & \\
\hline \multirow{2}{*}{ sqrt(I_A_4) } & 495.000 & $* * *$ & 527.000 & $* * *$ & 486.000 & $* * *$ \\
\hline & $(59.600)$ & & $(56.100)$ & & $(48.000)$ & \\
\hline \multirow{2}{*}{ Constant } & 3554000.00 & $* * *$ & 3564000.00 & $* * *$ & 3658000.00 & $* * *$ \\
\hline & $(248000.00)$ & & $(246000.00)$ & & $(215000.00)$ & \\
\hline No. of obs. & 579 & & 579 & & 579 & \\
\hline Adj. R2 & 0.57 & & 0.58 & & 0.57 & \\
\hline F stat. & 78.28 & & 98.69 & & 78.28 & \\
\hline Root MSE & 0.15 & & 0.15 & & 0.15 & \\
\hline
\end{tabular}

Regions having more personal computers per 100 people had a higher quality of education. Regions in which the number of cellular communication subscriber devices was higher also had a higher quality of education. In contrast, the lower share of digitalization of the networks in urban areas characterized the higher quality of education. The variable was statistically important, but the negative association was interpreted as follows: population consumed not only educational content but also other services. These were controversial results with respect to $\mathrm{H} 2$.

With regard to the quality of education, innovation activities had the strongest positive influence (H3). The level of innovation activity of organizations (I_A_1) had a strong positive effect on the quality of education. The implementation of technological, marketing, and operational innovations increased the quality of education at the regional level. The ratio of inventive activity (I_A_2) had the strongest influence on the dependent variable, as it stimulated the creation of business incubators based on universities, provided opportunities for internships in the best laboratories of the world, and much more. The volume of shipped innovative activities (I_A_4) had a weak positive influence because the production of innovative products, which was new in the organization in terms of profile and level of complexity, allowed the organization to enter new markets. In the final regression model, advanced production technologies (I_A_3) were statistically insignificant.

\section{Discussion and Conclusion}

Using a resource perspective, we analyzed the relationship between the factors of economic digitalization and the quality of higher education. The results were considered from a regional perspective. We used the methodology developed by Russian authors Balatsky and Ekimova (2009), and we regarded the education potential of regions as the quality of higher education. 
The results of our study showed that high levels of innovation activity were correlated with the high quality of higher education in the region. Thus, H3 was confirmed because the introduction of technological marketing and increased operational innovations had a strong positive relationship with the quality of education. The variables in the ratio of inventive activity demonstrated the strongest influence, thereby stimulating the creation of innovation platforms based on higher education institutions and providing opportunities for students to consolidate their acquired professional skills.

Innovative activities in regions, such as the creation of special educational platforms, transformed the educational process, increasing the accessibility of education and drawing the attention of students. The new technologies aroused the interest of students and involved them in the educational process. The studies reviewed reflected the results obtained, which showed that complex and challenging academic tasks based on students' prior knowledge allowed them to develop their own understanding of the content. These tasks were more likely to increase students' motivation and confidence in their cognitive abilities in applying technology. The formation and introduction of innovative tools in Russian regional universities may contribute to the emergence of strong universities that engage in applied and fundamental research, closely interact with industry, and introduce knowledge in research (Medinsky, 2018). Moreover, the introduction of innovative technologies would increase the attractiveness of universities and increase their effectiveness in preparing competitive specialists for the labor market.

Improving the quality of education in Russia's regions depends on digitization because of the introduction of the online educational environment in universities through the creation of online courses and their application in the educational process.

The hypothesis (H2) that the region's technological background has a positive influence on the quality of education was ambiguous. Research has shown that digital economic factors create stronger competitive advantages for regions in education and play an important role in regional development. The technological background will ensure a quality digital transformation in education, which will have a positive influence on the quality of education in general. However, the lower share of digitization of the network in cities characterized the higher quality of education in regions. This finding neither confirms nor rejects $\mathrm{H} 2$. The further development of the technological background will ensure the quick reorientation of education to accommodate new tasks in the labor market (Plotnikova, 2018).

The factors related to mobile and Internet activities (H1) had a weak negative influence on the quality of education in the region. This finding is explained by the following: according to the requirements of the Ministry of Higher Education, any educational organization should have a personal website, which is the reason that the share of such educational organizations is high. Another statistically significant variable related to mobile and Internet activities was the share of organizations using Internet access. It had a slightly negative influence, but it was statistically significant. This influence could be interpreted as the gap between educational organizations and real sector enterprises in Russia. Unfortunately, the educational process in educational organizations lacks the support of industry professionals.

The factors related to mobile and Internet activities include entertainment as well as the educational environment, which could have affected the negative dynamics of the indicator (Chen, 2019). According to statistics, many students spend much time in contacting social networks or playing games, which has a negative influence on the educational process (Wang, 2013). 
Our study revealed that the factor of economic digitalization led to a stronger competitive advantage for regional education, and it played an important role in regional sustainable development. Based on the findings of this study, it could be concluded that digitalization has a positive influence on the assessment of the quality of education in Russian regions. In general, the introduction of digital technologies in various areas, including education, allows for improving quality and contributes to further economic development. Moreover, during the current pandemic, the use of distance technologies and online courses is inevitable. Their introduction is aimed at increasing the level of safety, particularly regarding the health of students, administrative staff, and teaching staff.

\section{Acknowledgements} 20012.

The reported study was funded by RFBR according to the research project No. 18-310-

\section{References}

Balatsky, E.V., Ekimova, N.A., 2009. Educational Rating of Russian Regions. Available Online at http://kapital-rus.ru/articles/article/44/, Accessed on June 22, 2020

Barney, J., 1991. Firm Resources and Sustained Competitive Advantage. Journal of Management, Volume 17(1), pp. 99-120

Barney, J., Wright, M., Ketchen Jr. D.J., 2001. The Resource-based View of the Firm: Ten Years after 1991. Journal of Management, Volume 27(6), pp. 625-641

Cervantes, M., 2017. Higher Education Institutions in the Knowledge Triangle. Foresight and STI Governance, Volume 11(2), pp. 27-42

Chen, S., 2019. The Influence of Internet on College Education Management and Countermeasures. Journal of Physics: Conference Series, Volume 1345(4), pp. 1-4

Chen, T., Peng, L., Yin, X., Rong, J., Yang, J., Cong, G., 2020. Analysis of User Satisfaction with Online Education Platforms in China during the COVID-19 Pandemic. Healthcare, Volume 8(200), pp. 1-26

Dachyar, M., Yadrifil, Pratama, N.R., 2015. Development of Strategy Model for Organizational Innovation through Information Systems in Higher Education in Indonesia. International Journal of Technology, Volume 6(2), pp. 284-290

Federal Service State Statistics, 2020. Available Online at https://rosstat.gov.ru/anketa1-4 on November 22, 2020

Grinchak, H.P., Bogachyov, V.R., Kudrevich, V.V., 2020. Digital Economy of the Russian Federation. International Journal of Humanities and Natural Sciences, Volume 3(2), pp. 30-33

Kenneth, V.O., 2008. The Influence of the Internet on Education. Available online at https://classroom.synonym.com/influence-internet-education-6593610.html

Korableva, O., Durand, T., Kalimullina, O., Stepanova, I., 2019. March. Studying User Satisfaction with the MOOC Platform Interfaces using the Example of Coursera and Open Education Platforms. In: Proceedings of the 2019 International Conference on Big Data and Education, pp. 26-30

Mansell, R., Wehn, U., 1998. Knowledge Societies: Information Technology for Sustainable Development. Oxford University Press 
Medinsky, S., 2018. Some Features of Commercialization of Innovative Educational Services in Conditions of Implementation of Digital Technologies. Izvestia St. Petersburg State University of Economics and Technology, Volume 2(110), pp. 139-144

Plotnikova, E., 2019. Digitalization of Education in the Leading Universities of Saint Petersburg. In: IOP Conference Series: Materials Science and Engineering, Volume 497, pp. 1-6

Popova, O.I., Gagarina, N.M., Karkh, D.A., 2020. Digitalization of Educational Processes in Universities: Achievements and Problems. In: International Scientific Conference "Digitalization of Education: History, Trends and Prospects" (DETP 2020), Atlantis Press, pp. 741-745

Regions of Russia, 2018. Socio-economic Indicators. Available Online at http://www.gks.ru/bgd/regl/b18_14p/Main.htm, Accessed on June 22, 2020

Rothaermel, F.T., 2012. Strat. Mgmt.: Concepts and Cases. McGraw-Hill/Irwin, p. 5

Prahalad, C.K., Hamel, G., 1997. The core competence of the corporation. In: Strategische Unternehmungsplanung, Berlin, pp. 969-987

Sangrà, A., González-Sanmamed, M., 2010. The Role of Information and Communication Technologies in Improving Teaching and Learning Processes in Primary and Secondary Schools. Association for Learning Technology Journal, Volume 18(3), pp. 207-220

Sharma, D., Bhattacharya, S., Thukral, S., 2019. Resource-based View of Corporate Sustainable Financial Reporting and Firm Performance: Evidence from Emerging Indian Economy. International Journal of Business Governance and Ethics, Volume 13(4), pp. 323-344

Shcherbina, A.I., 2020. The Information and Communication Space of Education: Toward Digitalization. In: International Scientific Conference "Digitalization of Education: History, Trends and Prospects" (DETP 2020), Atlantis Press, pp. 898-901

Sukhanova, P.A., 2015. Model of Regional Innovation System: Domestic and Foreign Approaches to the Study of Regional Innovation Systems. Bulletin of Perm University. Series: Economics, Volume 4(27), pp. 92-102

Suwartha, N., Berawi, M.A., 2019. The Role of UI GreenMetric as a Global Sustainable Ranking for Higher Education Institutions. International Journal of Technology, Volume $10(5)$, pp. 862-865

Usarova, D.A., 2018. Information Technologies as a Motivating Factor in Students' Active Learning. Young Scientist, Volume 24, pp. 335-336

Velichenkova, D.S., Rodionov, D.G. Skhvediani, A.E., 2017. Comparison of the Methods of Rating Universities. In: Proceedings of the 30th International Business Information Management Association Conf. IBIMA 2017 Vision 2020: Sustainable Economic Development, Innovation Management, and Global Growth, pp. 2057-2061

Wang, J., 2013. What Higher Educational Professionals Need to Know about Today's Students: Online Social Networks. Turkish Online Journal of Educational Technology, Volume 12(3), 180-193

Wernerfelt, B., 1984. A Resource-based View of the Firm. Strategic Management Journal, Volume 5, pp. 171-180 